\title{
FRONTIERS OF TEACHING AND LEARNING INNOVATION IN ENGINEERING EDUCATION IN China - A Case of Tsinghua University
}

\author{
Shuangmiao Han $^{\text {a }}$ \\ University of Oxford \\ Zhou Zhong \\ Tsinghua University \\ Wei Li \\ Tsinghua University
}

\begin{abstract}
This investigation concerns the latest teaching and learning innovations in Chinese engineering higher education with special reference to Tsinghua University in Beijing, a leading university of China. Set in the context of rapid enrolment expansion in Chinese higher education since entering the 21st century, the study addresses how university engineering education innovated their contents and modes of teaching and learning to foster top-level talent, enhance relevance and responsiveness of education against rising number of students, scale of knowledge, and labour market demand, through content analysis of 163 award-winning programmes. The study also presents five case studies from Tsinghua University that have won recent regional and national awards under China's Higher Education Teaching and Learning Award scheme in 2012-2013 and in 2014 respectively. The data for the present investigation comes from a rich set of first-hand data of those wining institutions' award applications and collected from field visits by the present authors. The study further proposes a framework for designing and implementing engineering education programme. It is hoped that such a Chinese perspective could contribute to the global dialogue on teaching and learning in engineering education.
\end{abstract}

Keywords: engineering education, China, teaching and learning, innovation

\section{Introduction}

The latest four-yearly Beijing Higher Education Teaching and Learning Awards of 2012-2013 presented over 160 out of 663 awards to engineering programmes in about 40 higher education institutions (HEls). Some of the successful applicants also won national awards of this kind in 2014. Those awards represent the frontline of teaching and learning innovation in engineering education of both global to national competitiveness and regional to local embeddedness.

This paper represents a comparative study of the award-winning programmes with case studies to analyze the following research question: What are the teaching and learning innovations in engineering education in China, with special reference to national leading universities located in Beijing?

Engineering has become the biggest sector in Chinese higher education and Beijing has the largest cluster of engineering institutions in China, encompassing many national leading research universities as well as community colleges. For this reason, Beijing is selected as the area providing main data for this study's analysis.

\footnotetext{
Correspondence can be directed to: shuangmiao.han@education.ox.ac.uk
} 
Through a thematic review of engineering education's teaching and learning innovation engaged in universities in Beijing, the study attends two key themes: (1) students' holistic competence, achieved mainly through engaging problem-based learning (PBL), establishing a triple helix of teaching-research-industry and enhancing internationalisation; and (2) institutional capacity building, which are mainly reflected through curriculum and faculty development. The study then turns to Tsinghua University with reference to its five innovative engineering education projects that have won regional/national awards. Tsinghua is chosen for two reasons. First, Tsinghua is one of the best universities in China with indisputable strengths in its engineering education. In the latest QS World University Ranking (2015), it ranked $17^{\text {th }}$ in terms of engineering education, $25^{\text {th }}$ in overall score around the world, and $1^{\text {st }}$ in China in both categories. The second has to do with data availability.

Part 2 of the paper provides the context of engineering education in China and some challenges encountered in the process. It is followed, in part 3, by an introduction of the CDIO (ConceiveDesign - Implement- Operate) initiatives to provide reference to analysis of this study. In part 4, the study presents a comparative analysis of 163 award-winning engineering education programmes undertaken by universities in Beijing. It focuses on two themes, that is, students' holistic competence, and institution's capacity building, with incorporation of PBL, teaching-research-industry triple helix, internationalisation, as well as curriculum and faculty development. Those themes serve as a framework for further analysis of five cases in Tsinghua, as presented in part 5 . The paper concludes with a framework for designing engineering undergraduate education with consideration of the above analysis and the CDIO initiative.

The paper seeks to provide a better understanding of the latest teaching and learning innovations in Chinese engineering higher education, explore patterns for their successes and implications for engineering education in the world. It is also hoped to abstract a conceptual framework for designing engineering students' education for further guidance.

\section{Engineering Education in China: Teaching and Learning Innovations}

\section{Challenges to Engineering Education}

As a rapidly industrialising nation, engineering talents are crucial to China's development from agriculture to aerospace. Engineering education is the biggest sector in the Chinese higher education system. Over 1,000 universities and colleges (accounting for $90 \%$ of four-year $\mathrm{HEIs}$ ) in China provide engineering education. In 2010, China has 3.7 million undergraduates and 470,000 postgraduates studying engineering (National Bureau of Statistics of China, 2014).

Engineering education in China is facing growing challenges. Some of the most important issues are: (1) how to raise its education quality to cultivate a diverse range of innovative talents and maintain the total system's grow towards a $40 \%$ gross-enrolment-rate target by 2020 ; (2) how to balance teaching and research when universities are placing more emphasis on research performance and administrative efficiency, but less on fostering teaching skills; and (3) how to train students with a core set of knowledge, skills and competence for future engineers through closer education-industry alignment in the context of rapid knowledge explosion and skills upgrading. With regards to research universities, there is also a key challenge of how to translate institutional research leadership into teaching capacity.

\section{China's Excellent Engineers Plan}

Confronting these challenges, China has in recent years put forward a series of national initiatives to strengthen engineering higher education in recent years. The latest one is the "China's Excellent Engineers Plan 2010-2020" ("The CEE Plan"), co-funded by the Ministry of Education, Chinese Academy of Engineering and over a score of national ministries and professional engineering associations. The Plan aims to innovate engineering education in order to better align engineering education with national development strategy, make closer links between education and industry, 
enhance the student's holistic development and social responsibility, and strengthen international competitiveness of China's engineering talents. The CEE Plan has adopted five main measures: (1) closer education-industry partnerships in planning, teaching and learning; (2) raising engineering and innovation skills through setting up a network of national engineering training centers for student internships in industrial enterprises; (3) reforming university faculty employment and promotion policies to support industrial fellowships for engineering faculties; (4) increasing funding in national studying abroad schemes for engineering students and scholars; (5) joint education and industry effort to establish national standard for engineering talent, including a framework for engineering higher education qualifications (Zhang, 2010). Currently, the CEE Plan encompasses over 400 universities' undergraduate programmes and over 120 postgraduate programmes involving several million students. It is envisioned that the CEE Plan will have strong impacts on developing the Chinese engineering education system.

\section{China's Landmark Initiatives to Promote Teaching and Learning in Higher Education}

Teaching and learning innovations has long been a focus of education reforms and innovations in China. The higher education sector, presents dual development paths comprising an elite route (for research universities) and a general route (for all or majority of HEls). Most of the time, they progress in parallel with different strategic plans, focuses and resources; sometimes, they will adopt a merged route before new strategies (such as non-targeted nationwide education policies) for sustained specialisation are created.

The CEE Plan is a typical case in question. It builds on early institutional to national quality initiatives and works to mutually reinforce a series of other ongoing initiatives aiming at promoting quality across the higher education system.

For the general route, China launched in 1994 a project entitled "Towards the 21st century Plan of Teaching, Learning and Curricular Reform in Higher Education", aiming at examining and upgrading all major aspects of teaching and learning concerning ideas, structure, contents, methods, etc. in higher education. On this basis, in 1997-1998 China rationalised the national inventory of academic subjects and consolidated 504 subjects into 249 ones in 71 categories in 11 disciplines, including creating a new primary category of management studies and adding 74 new subjects. Then in 1999 China began an unprecedented enrolment expansion, especially in undergraduate education (Figure 1). As a result, engineering education, as the largest sub-sector, was significantly affected both in terms of quantity and quality. The rapid growth caused serious quality concerns.

Figure 1 Total student enrollments, 1998-2013 (ten thousand)

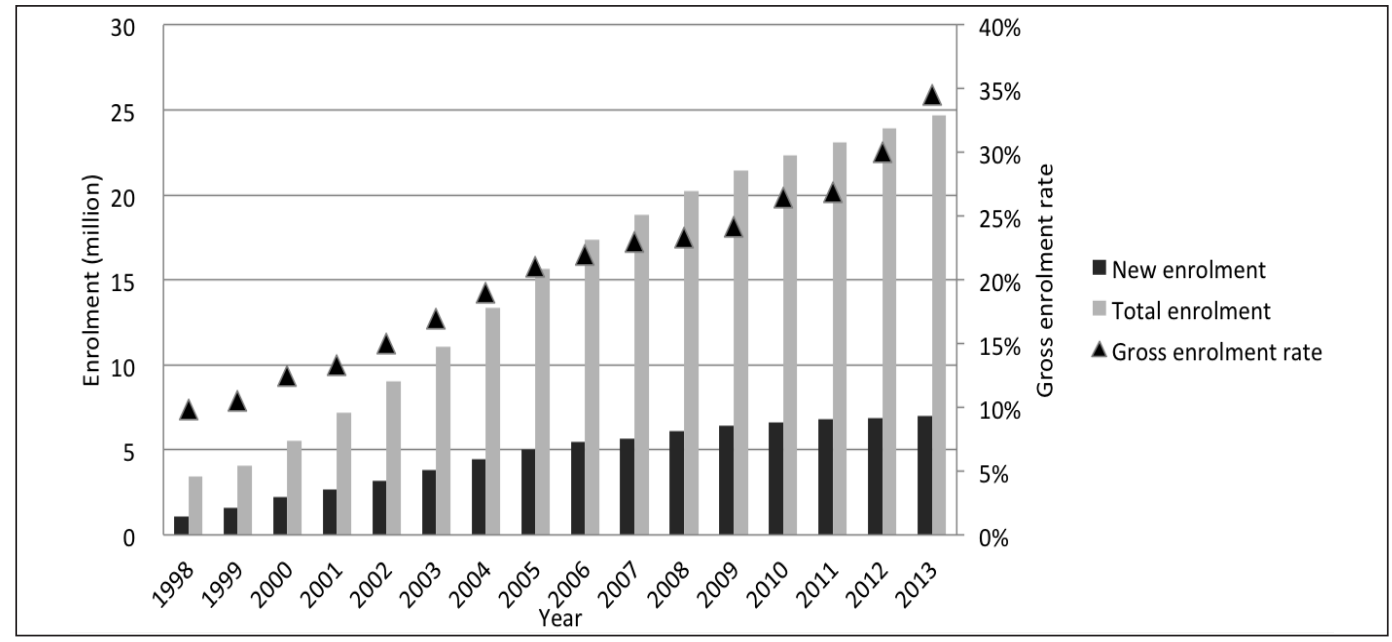

Source: National Bureau of Statistics of China, 2014 
For the elite route, through concentrated investment, in 1995 China launched the "Project 211" aiming at comprehensive capacity-building of 100 or so first-class universities and academic disciplines in service of national strategic development priorities for the 21st century. Then in 1998, China launched the world-class university building initiatives "Project 985", expanding from nine institutions to 39 research-intensive universities from the Project 211 Group. Both projects are in progress till today, respectively into the fourth and third five-year development phases.

A brief delineation of China's engineering education and higher education as a whole provides the context for analysis of teaching and learning innovations in Chinese engineering higher education.

\section{The CDIO Initiative and its Application in China}

The CDIO Initiative is an innovative framework for designing, operating and evaluating undergraduate engineering education. CDIO, referring to "Conceive- Design- Implement-Operate", stresses the fundamental elements of engineering education in real-world situations. The purpose of the initiative is to provide standards for design and assessment of engineering education programmes.

Engineering education is a central topic in higher education. Felder (1984) noted that engineering educators only "teach primarily mechanics" and use "memorization and routine application" rather than "reasoning methods" and "analysis, synthesis and evaluation". He believed that engineering education discourages creativity and independent thinking. Though some scholars have optimistically believed that undergraduate engineering education has been gradually changed from passive knowledge learning to a holistic approach that integrate knowledge and skills throughout the curriculum with a focus of human development (Lohmann, 1991; Bordogna et al., 1995), some explorative studies contradict the belief. For example, some studies found that engineering education sometimes fail to contribute to students' intellectual, creative and critical thinking development (such as in Felder and Brent, 2004; Goel and Sharda, 2004).

In this age of globalisation, engineering education, especially at undergraduate level, has gained increased significance. Various standards have been proposed in which the study finds three shared themes with what to expect to engineering students (such as in National Academy of Engineers, 2004; Goel, 2006; Criteria for Accrediting Engineering Programs, 2014). These are: (1) professional knowledge and skills, including technical competence, analytical skills, the ability to design and experiment; (2) the ability to identify real-world problems and apply knowledge and skills to their solving; and (3) holistic competences in which creativity, team-working in multidisciplinary environment, resilience, communication, work ethnic and global understanding have been constantly stressed.

Among various standards and frameworks, the CDIO Initiative is one of the most well-known and widely used one. It was initiated by the Massachusetts Institute of Technology (MIT) and further developed with collaboration among MIT and three other universities. The CDIO designs a framework that sets a series of goals for undergraduate engineering education and serves as indicators for outcome-based assessment. The 12 CDIO standards concern six parts (Table 1).

Table 1 CDIO Standard

\begin{tabular}{l|l}
\hline $\begin{array}{l}\text { Program Philosophy } \\
\text { Curriculum Development }\end{array}$ & $\begin{array}{l}\text { CDIO serves as the context for engineering education } \\
\text { Concrete and detailed learning outcomes; integrated curriculum with introductory } \\
\text { courses in engineering knowledge and essential personal and interpersonal skills; } \\
\text { curriculum with design-build experiences } \\
\text { Workspace and laboratories for practical learning }\end{array}$ \\
$\begin{array}{l}\text { Workspaces } \\
\text { Innovative teaching and } \\
\text { learning }\end{array}$ & $\begin{array}{l}\text { Integrated learning experiences and active experiential learning methods } \\
\text { Faculty development } \\
\text { Evaluation }\end{array}$ \\
\hline
\end{tabular}

Source: Worldwide CDIO Initiatives, n.d. 
The CDIO Syllabus is composed of four sections, setting a broad range of knowledge, skills and attitudes engineering students need to acquire.

The first is "technical knowledge and reasoning" ability, including understanding of "core" engineering fundamental knowledge and "advanced" engineering fundamental knowledge. The second is "personal and professional skills and attributes" that are fundamental for students' holistic development as successful engineers and as future leaders. This category includes skills in engineering reasoning and problem solving, experimentation and knowledge discovery, system thinking, personal skills such as perseverance and flexibility and critical thinking, as well as professional skills such as ethnics, integrity and proactive career planning. The third refers to "interpersonal skills", including team working and communication (written, multimedia, graphical, oral, interpersonal and foreign language). The last one describes the process of "Conceiving, Designing, Implementing and Operating Systems in the Enterprise and Societal Context". The CDIO Syllabus differs from previous standards in that it takes account of the unique traits of engineering education and engineering professions. "Conceiving" refers to the preparation work of viewing engineering education, determining its goals and requirements and making sure that the system can function properly with satisfactory outcome. "Designing" is the process policy makers utilize their knowledge of professional and external contexts to set the engineering system and curriculum. "Implementing" phase includes hardware manufacturing process, software implementing process and hardware and software integration; it also includes the verification and validation of the process and products, and implementation management. "Operating" tries to optimise the operations to support the system's sustainability, improvement and evolution. CDIO forms a cycle for designing an engineering education that caters to real-world problems and needs.

The CDIO standards and syllabus have been implemented in HEls around the world. It was firstly introduced into China by Shantou University, and gradually been adopted by other universities in developing and reforming their undergraduate engineering education (Zha, 2008). Based on the framework, the study uses the award-wining cases in the China's Higher Education Teaching and Learning Awards in 2012-2013 to construct the frontiers of innovations in teaching and learning in engineering education in China.

\section{A Comparative Analysis of the Award-winning Engineering Education Programmes}

The study conducted a comparative analysis of 163 award-winning programmes that have won the Beijing Higher Education Teaching and Learning Awards of 2012. Based on content analysis, two themes emerged in explaining the uniqueness of those projects, that is, the focus on students' holistic competence and the incorporation of institutional capacity building into the designing and implementing process.

\section{Students' Holistic Competence Development}

In the CDIO frameworks, engineering students' holistic competence includes the acquirement of core and advanced engineering fundamental knowledge, professional skills, personal skills and interpersonal skills. In this sense, those successful programmes have put students' holistic development at the core of programme design and implementation, rather than merely focusing on quantitative-based outcome and acquirement of subject-related knowledge and skills. Two shared characteristics have stood out in those programmes.

(1) Clear goal-setting with strong emphasis on engineering disciplines

The goals of the majority of cases under analysis can be classified into three categories, that is, to train students with creativity, practical knowledge and skills, as well as research abilities. It largely reaches CDIO's goals in engineering education's curriculum and system designing.

The first set of goals is to train engineering undergraduates with "creativity" to identify and resolve problems. In the overall 163 programmes, 72 programmes set their aims at cultivating 
creative talents, 37 of which clearly indicate "creativity" in their programme titles. For example, the programme initiated by Beijing University of Aeronautics and Astronautics highlights the importance in building undergraduates' creativity through analysing and absorbing experiences of world-class universities.

The second set of goals emphasises the training of undergraduates with practicability. Engineering disciplines, unlike humanities or natural sciences, focus on practical skills in solving real-world problems. Most universities combine their disciplinary advantages to train talents with skills of practical application. For example, Beijing Information Science and Technology University develops a special programme to train Communication Engineering students whereas China University of Mining and Technology (Beijing) initiates a programme for training Coal Geology undergraduates in line with current industrial needs.

The third set of goals focuses on the training of undergraduates with research abilities through teaching and learning innovations. For example, Tsinghua University collaborates with Nanjing Aeronautics and Astronautics University and Nanjing University of Technology to advocate researchbased teaching in undergraduate engineering programmes.

(2) Approaches: Problem-based learning (PBL), teaching-research-industry helix and internationalisation

The three most common approaches used by the majority of universities are problem-based learning $(\mathrm{PBL})$, building of a triple helix of teaching-research-industry and internationalisation.

As a student-centred pedagogy, PBL differs from traditional practices of teaching, such as cramming and memorisation, in most Chinese universities. Those award-winning programmes focus on students' holistic competence training through PBL, including opening labs specifically to undergraduates, designing educational practical courses, building practice teaching bases inside and outside campus, etc. For example, Beijing Institute of Technology initiates a programme to train students that satisfy the national strategic needs for new energy automotive industries. Its strategies include the founding of a new energy automotive undergraduate laboratory and building of a practical teaching platform to support students' technological innovations. It allows students to experience open-ended problems through which both their knowledge and thinking strategies were improved.

Another approach applied by those universities is to build a triple helix of teaching-researchindustry. This sets in contrast to the traditional way of teaching and research in which students learn and practice what are perceived to be important merely by academics. It is one of the most convenient ways to understand the enterprise and societal contexts for engineering education, as well as to ensure universities' responsiveness and responsibility and students' employability. For example, Beijing University of Technology and Beijing Software Products Quality Inspection Center form a new undergraduate internship model-guided by universities, linked through the government and operated in enterprises.

In addition, global competence is key to engineering education in this age of globalisation. Many of the programmes analysed in the study pay special attention to internationalisation, ranging from internationalisation of curriculum to international communication and collaboration. For example, Beijing Institute of Civil Engineering and Architecture's programme for Water Supply and Drainage Engineering major builds a China-US " $3+1$ " and " $2+2$ " programmes that train students with international scope and abilities with global application.

The three approaches shared by present cases contribute to the making of universities a talent training base to produce high quality engineers in line with real-world needs. It caters to the CDIO's emphasis in training young engineers in enterprise and societal contexts with essential professional, personal and interpersonal skills such as team working and communication. Such approaches also align with the CDIO standards such as designing, such as building workspaces and employing experiential and hands-on learning methods. 


\section{Institutional Capacity-Building}

Another important theme emerged in the study is those programmes' incorporation of institutional capacity building in designing and implementing innovative engineering programmes. For one thing, it contributes to the overall development of institutions involved in all aspects and therefore is able to utilise more resources. For another thing, it directly addresses the sustainability of programmeshow to form a benign cycle to allow continuous development of innovations. In this respect, three things are deliberately incorporated into the programmes-curriculum building, faculty development, and assessment.

(1) Integrated curriculum building

Curriculum development forms a significant part in the CDIO standards and remains an important part in China's innovative teaching and learning in engineering education. An important aspect in those innovations is their focus on the building of a comprehensive and integrated curriculum, rather than the traditional 'tinkering' practices in which a new programme only targets at to improve certain specific areas concerning the curriculum.

The integrated curriculum building represents the following characteristics: a trend towards multi-disciplinary, a balance between foundation and advanced courses, and a focus on students' practical abilities. For example, Beijing Institute of Technology's training of new energy automotive talents creatively sets the curriculum in the majors that encompass multi-disciplinary knowledge, such as in Mechanical Engineering, Electrical Engineering and Electronic Engineering. It reforms its curriculum with introductory fundamental courses and advanced practical courses. In addition, as a 'whole package', it also reforms its teaching through compiling a new set of textbooks that integrates interdisciplinary knowledge to keep it more up-to-date with industrial needs.

(2) Faculty development

The significance of faculty development pertaining innovative engineering programmes is twofold. First, faculties are the most important actors in designing innovative programmes for engineering education. Second, they are the direct implementers and facilitators of those programmes. Therefore, making faculty development a part of those programmes has great impact on their actual delivery. Moreover, raising the abilities of faculties contributes to overall institutional development.

In the analysed cases, faculty development has been integrated in many of the programmes, but normally not as the major goal. An example can be seen from Beijing University of Chemical Technology, whose strategies include building high-quality "double qualified teachers". The term "double qualified teachers" refers to teachers with both theoretical knowledge (education background) and practical knowledge (practical experiences).

(3) Evaluation and assessment

The standards for undergraduate engineering education have also changed, as indicated in many programmes, to align with innovative teaching and learning strategies and practices. The changing characteristics of evaluation and assessment in the 163 universities include: emphasis from external assessment to self-motivation and self-assessment; from knowledge to skills and creativity; and from consideration of exam performance to students' holistic performance. For example, the Engineering Electromagnetic Field's teaching and learning innovation includes reforms on evaluation system. It expands to include students' performance in classes and in experiments, in-class quizzes, research participation and final exams. It also helps to indicate the outcome of teaching and learning innovations employed by the university.

\section{Case Studies}

This section moves from a holistic picture of universities in Beijing to a narrower focus on Tsinghua University, as a national leading university with special strength on engineering education. It presents 
five case studies of innovative undergraduate engineering programmes in Tsinghua, all of which have won the latest regional or national awards for China's Higher Education Teaching and Learning Awards in 2012-2013. They largely represent China's frontiers of teaching and learning innovations in engineering education.

\section{The Yao Class of Tsinghua Computer Science: A Model for Elite Engineering Education}

A special designed programme, aiming at cultivating top engineering undergraduate students in computer science, was initiated by Professor Yao Qizhi (Andrew Chi-Chih Yao) in 2005 in Tsinghua University. The Xuetang Special Pilot Computer Science Class (Yao Class) sets up a model for teaching and learning innovations in the field of computer science. The programme has been recognised worldwide as one of the best undergraduate programmes.

The founder of the programme, Professor Yao, is a leading expert in computer science and a winner of the Turning Award. He believes that China's engineering undergraduates' lack of research foundation, field knowledge and creativity is mainly due to two reasons: over-emphasis on technical problem-solving rather than in-depth theoretical research; and narrow focus on pure knowledge transfer rather than students' creative and critical thinking abilities. To solve these problems, the programme designs and implements several strategies.

(1) Setting programme goals and benchmarking

The programme differs from traditional Chinese undergraduate programs, clearly setting its goals as training top undergraduates in computer science with standards aligning with MIT, Stanford and other prestigious universities around the globe. Through benchmarking with other top engineering education programmes, the Yao Class sets up a model taking into consideration of students' aptitudes and the industrial, national and global needs for innovative talents in computer science.

(2) Internationalisation

As an intensive international teaching programme, the most distinctive feature of the programme is its unique international talent cultivation model. Students in Yao Class are funded to participate in exchange programmes with universities such as MIT and Michigan; winter school with universities in Hong Kong; and other academic visits around the world. The multi-dimensional international platform enables students in the programme to acquire and experience the best engineering education in the world and to develop their transferable skills and global competence.

(3) Curriculum and faculty

The pilot programme designs and implements its own set of curriculum that consists of core classes and specialised classes. It restructures the knowledge system to focus on both basic and theoretical knowledge, and its application in real-world situation. Its goal is to train students with advanced knowledge in computer sciences that align with current industrial needs. The curriculum includes basic courses and research-oriented practice. The programme believes that it is of great significance to apply junior and senior undergraduates with real-world research opportunities. The thesis project is conducted by students with completion of one-semester research-based activities in world-class universities home and abroad.

The programme also invites world-renowned faculties around the globe for innovative instruction. All the core courses are instructed in English. In terms of pedagogy, it engages students in discussion, active learning, communicative skills and individualised programmes to their own interests.

\section{Teaching and Learning innovations in Mechanical Engineering: Curriculum Design and Research-Oriented Teaching}

Curriculum development is an integrated part in the CDIO initiatives, as indicated in the previous section. Curriculum and teaching is the key in knowledge transfer for students. The study analysed a 
case that jointly initiated by Tsinghua University, Nanjing Aeronautics and Astronautics University and Nanjing University of Technology. It is an innovative reform in teaching and learning in Mechanical Engineering. The programme is designed to solve problems in current teaching in China: large-size and unattractive class, low-degree of teacher-student interaction and students' lack of creativity. The programme focuses on research-oriented teaching and has been implemented in seven universities around China for ten years, attracting wide attention as a breakthrough in engineering education teaching.

(1) Research-oriented teaching

"Research-oriented teaching" is the philosophy of the programme to improve in-class teaching and out-of-class instruction in mechanical engineering. The basic innovation is the restructuring of content and textbooks to focus on theoretical knowledge in the field and real-world engineering cases identified through research. The way for instruction has been changed from cramming education to teaching that engages, challenges and provokes students. The faculty employs participatory teaching methods and increases student-teacher interaction to make the classes more fun and thought provoking. It is also beneficial for faculty to balance teaching and research and develop their professional skills through teacher-student interaction.

(2) Active participatory learning

On the other hand, students are encouraged to "learn in research and learn from research". They become more actively participated in in-class discussions and out-of-class research. A special designed approach is "open-ended cases", in which students are encouraged and guided by their instructors to explore many possibilities for problem solving in mechanical engineering.

Through interviews with students participated in the programme, they generally believe that the research-oriented teaching content and heuristic teaching methods intrigue their interests in the class and provoke their active discussion and interaction with instructors and further exploration and research outside class. Students are also impressed by instructors' humorous and interesting content and ways of delivery of the content.

\section{A Curriculum Reform in Electronic Engineering: A Theory-Driven Design}

The Department of Electronic Engineering in Tsinghua University has implemented a curriculum reform in order to tackle the increasingly tension created by an expansion of knowledge and limited in-class time. Unlike the previous case, the reform takes a holistic approach, using 'paradigm' as the fundamental criterion to transform the curriculum. The reform has been implemented within the department and attracted attention from home and abroad. Since 2010, Chinese universities such as the University of Electronic Science and Technology at Xi'an and Tianjin University, as well as world-renowned universities such as Stanford, MIT and Berkeley have arranged visit studies to the department. There are two key aspects in the reform.

(1) A theory-driven orientation

The reform is based on 'learning theory' and Kuhn's theory of 'Scientific Revolutions'. Through tracing back the history of electronic engineering and placing it within the disciplinary structure, the reform has proposed a knowledge structure for electronic engineering discipline to ensure the curriculum encompasses both a broad-based knowledge and professional expertise for engineering undergraduates.

(2) Structured curriculum

The three-layered structure of the newly reformed curriculum includes an introductory course, 10 core courses and 24 selective courses. The introductory course provides freshmen with a clear picture of the knowledge structure of sciences in general and electronic engineering in particular, so they can develop a better understanding of where they stand and where to go. The 10 core courses are revised and re-adapted from the original 14 courses to offer students a more condensed learning experience. The 24 selective courses, encompassing a broad range of topics in the field, provide students a more liberal way in pursuing their academic interests. 


\section{Experiential Learning: National College Student Intelligent Car Competition}

Tsinghua University, Beijing University of Aeronautics and Astronautics, Shanghai Jiao Tong University and other seven universities, in collaboration with the Freescale Semiconductor Company Limited (China), initiated a National College Student Intelligent Car Competition. The main goals are to improve undergraduate engineering students' practical knowledge and skills, creativity and team-working abilities, as well as their connection with real-world problems. The competition is designed for these purposes and serves as an important link for practical teaching. It is an innovative experiential learning practice designed for China's engineering students and has extensive influence on hundreds of universities and China's development for undergraduate engineering education. There are three main aspects that contribute to its success and students' holistic competence development.

(1) Theoretical exploration and practical application

It is believed that engineering is designed to better understand and change the world. Therefore, engineering education should focus on students' development in knowledge and skills with both theoretical and practical significance. The competition's philosophy is "learning by doing". It requires three students from different majors to form a team to complete a CDIO project in 10 months. It gives students an invaluable opportunity to apply what they have learned in class to realworld contexts, and to become familiar with engineering product development through conceiving, designing, implementing and operating.

(2) Multi-disciplinary innovative teaching platform

The design of the competition helps to bring together students from multi-disciplinary background in engineering, such as Automotive Engineering, Computer Science, Electric Engineering, Electronic Engineering, Instrument Science and Mechanical Engineering. The infusion from multidisciplines contributes to students' interdisciplinary learning and innovation. Students can learn from their peers from all kinds of engineering disciplines. It also enhances the enjoyment of the competition. Another important aspect in the competition is its contribution to students' teamworking spirit and abilities. Through intensive working with peers and seniors, students are able to develop a better sense of team working that is essential for engineering projects.

(3) Teaching-research-industry

The competition, first started in 2005 , has formed a cycle of teaching-research-industry to support engineering education development. The competition contributes to the building of 131 Freescale Semiconductor's laboratories in 113 universities. These laboratories provide workspace for engineering students' practical learning. Based on these laboratories, those universities have developed related curriculum, teaching content and textbooks, and competition-related training. It also contributes to faculty's professional development. Some of the products and outcomes of those development and competition are also employed by companies for industrial uses.

\section{Engineering and Global Education: Cooperation between Tsinghua and the RWTH Aachen}

The cooperation between Tsinghua University and the RWTH Aachen, a research university specialising in technology in Germany, in Production and Automotive Engineering, a national awardwinning programme in innovative engineering education in 2014, started in 2000 under the initiatives by the two ministers of education in China and Germany. The 2-year master's programme aims to allow students in each institution an opportunity to experience different learning and research environments while further their global awareness. The goal of the programme is to 'learn together and research together', meaning the programme includes not only courses but also research projects and internships. Two key innovative aspects are reflected in the project.

(1) Cross-border cooperation and globalisation

In this age of globalisation, engineers are expected to acquire global competency, which includes not only the edge-cutting trends and skills in their chosen fields but also cross-cultural understanding and communication abilities. By being exposed to different learning and research 
environments, the project enhances engineering students' mobility while enriching their research experiences. In addition, the project improves the internationalisation of institutions as a whole.

(2) Sustainability: faculty development and strategic cooperation

One of the key determinants of a project is its sustainability. The Tsinghua-RWTH Aachen Cooperation focuses not only on students but also on faculties. Each year the two universities will exchange three to five faculty members to further develop their abilities in engineering teaching and research. Such arrangement would enhance the research cooperation and exchange between the two universities in the long run. Through the project, the two universities are able to establish long-term strategic partnership that will lead to more cooperation and better engineering education for their students.

\section{Concluding Remarks: A Framework for Engineering Talents Training}

From the above analysis, the study attempts to find the common ground for these innovative engineering undergraduate programmes. Those innovative programmes resonate the problems identified in the paper in the beginning, that is, the balance between quality and quantity, research and teaching, technical knowledge and general skills, and the connection between institutional leadership and teaching capacity. Those programmes are not designed specifically based on the CDIO standards, but many of them represent its goals and strategies throughout the designing and implementing of programmes, such as a focus on curriculum development and pedagogical innovations. There are five shared elements that contribute to the successfully implementation of these programmes: (1) a focus on knowledge exchange and curriculum development; (2) balance between basic and advanced knowledge, as well as theoretical exploration and practical learning; (3) advocacy of students' active and experiential learning; (4) advocacy of students' innovative and critical thinking abilities; (5) emphasis on real-world contexts and industrial needs.

Based on the analysis and the CDIO standards, the study develops an ideal framework for engineering undergraduate education (Figure 2).

Figure 2. An Ideal Framework for Engineering Undergraduate Education

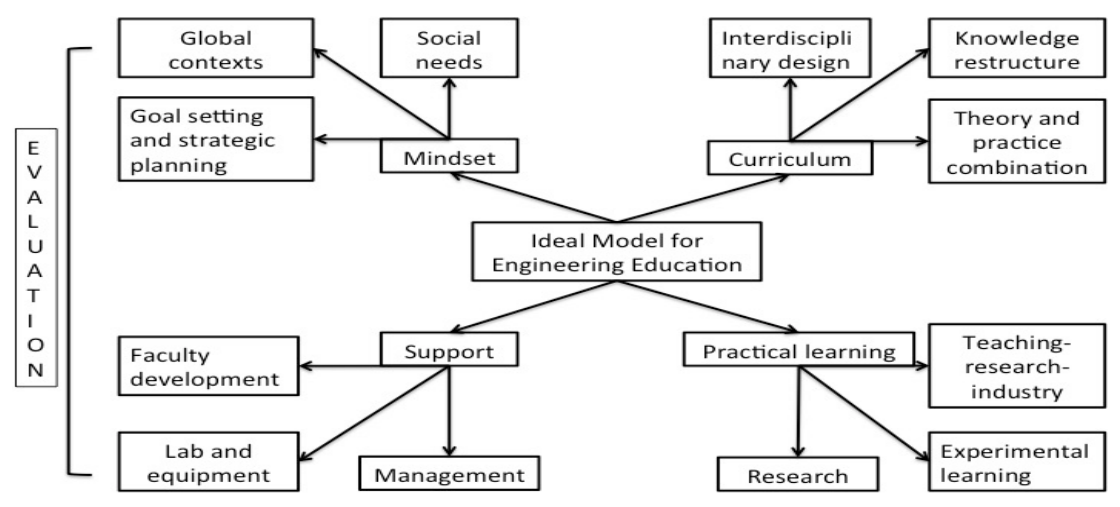

It is hoped that these experiences will provide enlightenment for development of global engineering undergraduate education. More specifically, it envisions an ideal model of developing engineering programmes in four aspects-mindset, curriculum, practical learning and support. Mindset means that actors involved in the designing and implementing phases should set their goals according to indigenous features of engineering education, global contexts and social needs, and make strategic planning. Curriculum is one of the most important aspects in innovative engineering 
programmes, in which three elements stand out: interdisciplinary design, a clear knowledge structure and a balance between theoretical and practical knowledge and skills. Practical learning has been frequently stressed both in cases analyzed here and in the CDIO standards. It is beneficial to expose undergraduate engineering students to research environment and engage them in experiential learning. Building a teaching-research-industry triple helix not only contributes to students' practical skills, understanding of real-world contexts and employability, but also institutional sustainable development. A successful engineering programme requires continuous support, especially in terms of faculty (their abilities and willingness), infrastructure (such as labs and equipment) and management (such as streamlining administrative procedures). In addition, a clearly designed, performance-based evaluation is essential in assessing the programmes' outcome. Institutions should set ex ante criteria for evaluation rather than ex post standards to justify the outcome.

In addition, through analysis of the 163 award-winning programmes and their comparison with the CDIO standards and syllabus, this study also identified four problems in existing programmes.

First, evaluation and assessment is still a weak link in forming the life cycle of engineering education development. Only a few programmes have indicated how to evaluate and assess the teaching and learning innovation they had employed for students' development. A proper set of evaluation standards should be made and adopted in accordance with programmes' design to measure their effectiveness and efficiency, and serves as the foundation for the next cycle of development.

Second, faculty should become more engaged in the designing and implementing processes. Strategies to improve faculties' knowledge and skills in professional, personal and interpersonal skills are also beneficial to students' development. It will also help integrate faculty in designing, implementing and evaluating the innovative engineering education.

Third, the analysed programmes primarily focus on students' professional knowledge and skills development. According to the CDIO standards, personal and interpersonal skills, such as perseverance, time-management, leadership and communication, are all integrated elements in training young engineers. However, those programmes fail to recognise their importance or integrated them into those programmes. It is important to note that what we need is more than engineers with expertise, but also responsible citizens and leaders.

Last but not the least, referring back to the CDIO process of 'conceiving, designing, implementing and operating systems', one of the weaknesses of current engineering programmes is a lack of a vision of the whole programme: how it will be conducted and where it will go. Most programmes are more like freewheel experimentation without a clear perception of the expected outcome and a sustainable operation system. In another word, institutions develop relevant programmes with innovative elements in order to tackle existing problems or meet local needs, normally without previous references or experiences, nor a holistic idea of how to use them as a way to enhance the whole engineering education system in China.

\section{References}

Beijing Education Commission (2013). China's Higher Education Teaching and Learning Award in 2012-2013: Application data of higher education institutions in Beijing (unpublished).

Bordogna, J., Fromm E., and Ernst, W. (1995). An integrative and holistic engineering education. Journal of Science Education and Technology, 4(3), pp.191-198.

Criteria for Accrediting Engineering Programs 2015-2016. (2014). Engineering Accreditation Commission. Available at http://www.abet.org/wp-content/uploads/2015/05/E001-15-16EAC-Criteria-03-10-15.pdf [Accessed 1 August 2015].

Felder, R.M. (1984). Does Engineering Education have anything to do with either? Engineering Education, 75(2), pp. 95-99.

Felder, R.M., and Brent, R. (2004). The intellectual development of science and engineering students part 1: Models and challenges. Journal of Engineering Education, 93(4), pp. 269-277. 
Goel, S. (2006). Competency focused engineering education with reference to IT related disciplines: Is the Indian system ready for transformation? Journal of Information Technology Education, 5, pp. 27-52.

Goel, S., and Sharda, N. (2004). What do Engineers Want? Examining Engineering Education through Bloom's Taxonomy. Proceedings of $15^{\text {th }}$ Annual Conference for the Australasian Association for Engineering Education, Toowoomba, Queensland, Australia, pp. 173-185.

Lohmann, J.R. (1991). Myths, facts and the future of U.S. engineering and science education. Engineering Education, 81 (3), pp. 365-371.

National Academy of Engineers (2004). The Engineer of 2020: Visions of Engineering in the New Century. Washington DC: The National Academies Press.

National Bureau of Statistics of China. (2014). Total student enrollments. Available at http://www. stats.gov.cn/english/ [Accessed 1 June 2015].

Quacquarelli Symonds (2015). QS World University rankings 2015/2016. Available at http://www. topuniversities.com/university-rankings/world-university-rankings/2015\#sorting=rank+regio $\mathrm{n}=+$ country $=+$ faculty $=+$ stars $=$ false + search $=$ [Accessed 20 September 2015].

Tsinghua University (2010). Tsinghua-RWTH Aachen Joint Master's Degree Programme. Available at http://www.ie.tsinghua.edu.cn/include/hotarticle.php?ty=76\&id=112 [Accessed 20 June 2014].

Worldwide CDIO Initiatives. (n.d.) CDIO Standards 2.0. Available at http://www.cdio.org/ implementing-cdio/standards/12-cdio-standards [Accessed 28 July 2015].

Zha, J. Z.. (2008). On CDIO model under "Learning by Doing" strategy. Research in Higher Education of Engineering, 3, pp. 1-9.

Zhang, W. W. (2010). The Ministry of Education initiated the "China's Excellent Engineers Plan. Education and Vocation, 2010 (19), p. 20.

Zhong, Z., Ulicna D., and Han, S.M. (2014). The EU and China: The race for talent-The relevance and responsiveness of higher education. In E. Beerkens, M. Magnan, M. Soderqvist and $\mathrm{H}$. van Liempd (Eds). Internationalisation of Higher Education An EAIE Handbook. Berlin: Raabe Academic Publishers, pp. 1-30. 
